\title{
The Extra Dural Hematoma Complicating a Decompressive Craniectomy about One Case
}

\author{
Bukasa Binene JC*, Benzagmout M, Chakour K and Chaoui FM \\ Department of Neurosurgery, University hospital Fez Morocco, Morocco \\ *Corresponding author: Bukasa Binene JC, Department of Neurosurgery, HASSAN II University hospital Fez Morocco, Morocco
}

\begin{abstract}
The extra-dural hematoma or epidural hematoma is a collection of blood formed between the dura mater and the internal table of the skull bone. The origin is traumatic most often causing an arterial lesion more particularly of the meningeal artery; this explains the topographical predilection of extra dural hematoma for the temporal zone with $50 \%$ of cases according to (BRICOLO 1984); rarely the cause may be a post-traumatic lesion of a venous sinus or a bone bleed at the level of the fracture site. In this respect, 5 to $10 \%$ of forms without fracture exist (BRICOLO 1984). Classic in traumatology and more readily the young subject $60 \%$ between 10 and 40 years. Beyond 60 years the dura matter adheres to the internal table of the bone and gives it a less releasable character in the area of Gérard Marchand which explains the rarity of this lesion after 65 years.
\end{abstract}

\section{Case Report}

Mr A. M, 21 years old, with no notable antecedents, smoking and alcoholism known as a motorcycle accident victim overturned by a car with a cranial impact point followed by immediate loss of consciousness, picked up by firefighters and sent to the emergency room; at admission the clinical examination found that the patient is unconscious, he smelled alcohol with a Glasgow score estimated at $7 / 15$, hemodynamically stable and blood pressure 120/60mmhg. Neurologic examination found a left anisocoria bilateral palpebral contusions with stigmata of otorrhagia in the left auditory canal, the rest of the clinical examination was normal. The body scan demonstrated foci of left and right parietal basal temporal hemorrhagic contusions were observed, diffuse cerebral edema with mass effect on the left ventricle and two non-displaced fracture lines of the right parietal bone. On the cervical and abdominal there was nothing to signal. The patient was intubated, sedated and ventilated and then sent to the operating room for a left fronto-temporoparietal decompression with a sub temporal craniectomy (Figure 1). The Intervention happened without incident, the patient remained intubated, sedated and ventilated. On day 1, a cerebral CT scan is performed and shows a voluminous contralateral frontal-temporal-parietal extra-dural hematoma with deviation of the median line and herniation of the brain through the craniectomy and a quasi-right hemisphere ischemia. The time to return to the operating room to evacuate the hematoma it makes the soul.

\section{Discussion}

Serious head injuries (GCS $\leq 8$ [1]) remain a serious public health problem in developed countries because of the major sequelae they cause to a young and active population: approximately $43 \%$ of trauma patients cranial need a third person in everyday life [2]. The cranial box is an inextensible container, in which a physiological Intracranial Pressure (ICP) prevails, normally: 5 to $15 \mathrm{mmgh}$. PIC increases with slanting position, jugular vein compression, nociceptive stimuli, agitation, respirator mismatch, endothoracic pressure, hypercapnia, hypoxia, epileptic seizures, temperature, hyponatremia ( $\mathrm{Na}<120 \mathrm{mmol} / \mathrm{l})$ and Hypertension. The content of the skull can be divided into three parts: the brain parenchyma which accounts for $90 \%$ of the contents (including intra and extracellular fluids and the cell membrane), arterial and venous blood volume, and Cerebrospinal Fluid (CSF) which count for the remaining $10 \%$.

As a result, an intracranial Hypertension that is a conflict between the container and the content can develop when it changes in volume of one of these three elements of the content:

a) Due to a process occupying space (hydrocephalus, hematoma, tumor). 
b) Because of a cerebral edema reaction to a pathological process (head trauma, cerebral ischemia).

Only the volumes of CSF and blood (in its extra sinus venous portion) can be reduced to give space to the neo-volume, these are the only compensating elements. Once these compensatory mechanisms are exhausted, a small increase in volume leads to a significant increase in the ICP. Many pathological conditions are likely to lead to HTIC, of which cerebral edema seems to be the most common cause. The main risk of head trauma is the occurrence of HTIC incompatible with a sufficient Cerebral Perfusion Pressure
(CPP) [3], and responsible for the mortality found in $50 \%$ of traumatized cranial [4], as shown by the curve pressure-volume of Langfitt. The decompressive craniectomy, by the removal of a large bone component associated with a sub temporal craniectomy and a plasty of enlargement of the dura mater, is proposed in certain refractory HTIC situations in a context of progressive secondary lesions. His indications are difficult to ask. Its use seems to be associated with an improvement of the vital prognosis but remains controversial with regard to the functional prognosis of the survivors [5].
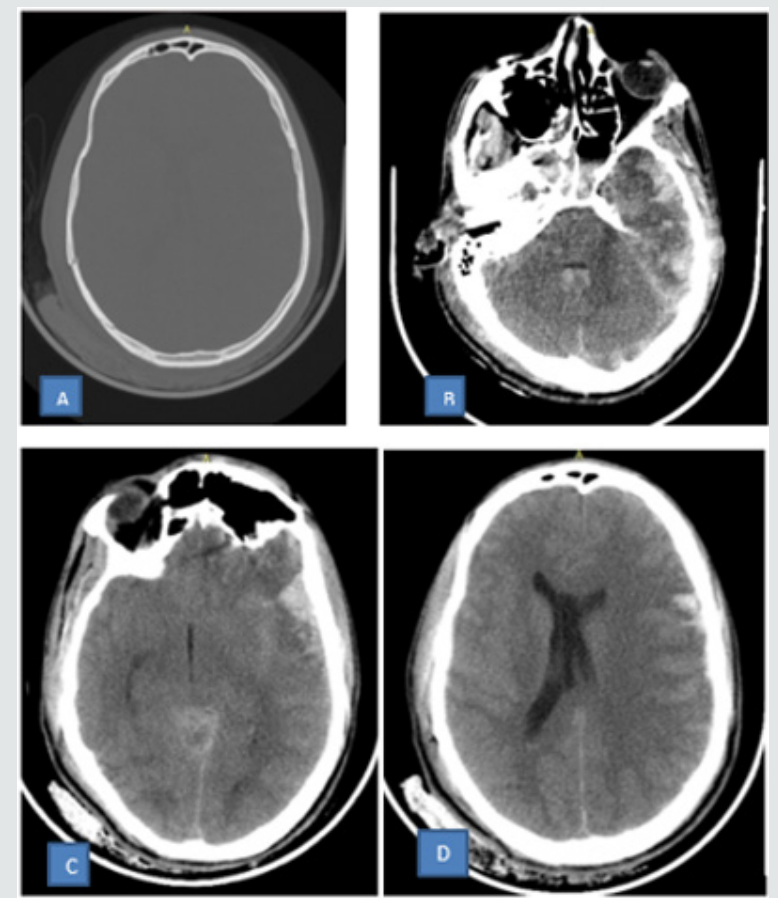

Figure 1: Day zero Cerebral CT scan shows on the parenchymal window patches (B, C, D) of left temporo-parietal hemorrhagic contusion foci, diffuse edema with erasing of the basal cisterns and mass effect on the medial line and lateral ventricle. The bony window (A) shows a two contralateral non-displaced fracture line opposite some contusion focus.

This surgical technique was proposed in the early twentieth century to try to improve the prognosis of tumor resection surgery. Its effect is correlated with size of a craniectomy [6], observed at a scan by emergence of cisterns of a base and reduction of deviation of a median line. For twenty years, this technique has been used to treat refractory HTICs for any other treatment, especially after failure of barbiturate coma and hypocapnia. The study by Yoo et al, proves the effectiveness of this technique on the reduction of intracranial pressure. This work shows the rapid decrease in intraventricular pressure immediately after bone decompression (decrease of $50 \pm 16.6 \%$ of the initial value), the opening of the dura allowing a decrease in intracranial pressure of approximately $34.5 \%$ [7]. Historically, decompressive craniectomy has been used to treat intracranial hypertension secondary to Reye's syndrome in children [1,8]. Stefini et al. [9] have reported good results after craniectomy for the treatment of hemorrhagic infarction secondary to venous sinus thrombosis. In the surgical treatment of spontaneous hematomas, Dierssen et al. [10] found a significant improvement in the mortality rate in treated patients by evacuation of the hematoma with craniectomy compared to a series treated only by evacuation of the hematoma. Complications of the Decompressive Component $[11,12]$.

Complications of Craniectomy can be Divided into:

a) Early complications dominated by hematomas.

b) Secondary complications, mainly: Hydrome and infections.

a) Early Complications: [13] Precociously, hemorrhagic complications and hematomas are the main complications. Decompression and decline of ICP are likely to promote the development of contralateral acute or extradural subdural hematoma. The increase in haemorrhagic lesions with craniectomy has been described as being favored by small flaps that promote the formation of localized cerebral hernias. These complications and the continuation of intensive care surveillance justify the establishment or maintenance of postoperative monitoring of ICP.

b) Secondary Complications: After decompressive surgery, the brain undergoes several changes regarding: hemodynamics 
with venous drainage, cerebrospinal fluid movement, and general metabolism. This is more clinically evident in patients who experience improvement and subsequent deterioration of neurological status within a few weeks to months after decompressive craniectomy with concave depression above the flap site. This phenomenon has been described as the scalp flap syndrome. The neurological signs may be limited to fatiguability, discomfort, depression, intolerance to vibration, headaches, more rarely sensory and / or motor deficits that may appear.

In 1977, Yamaura et al. [14] published a study of 33 patients with the scalp flap syndrome after craniectomy, and reported neurological improvement after bone segment reimplantation in $88 \%$ of patients with mild symptomatology published a study of 5 cases with neurological deterioration after craniectomy, which was improved by cranioplasty [15]. Some authors have explained the physiopathology of this phenomenon by the transmission of atmospheric pressure to the cranial cavity. The treatment of this syndrome consists in reconstituting the skull by a cranioplasty. Fodstad et al. [16] Studied cerebrospinal fluid dynamics before and after cranioplasty, and found an increase in cerebrospinal fluid pressure after cranioplasty in patients with this syndrome. Winkler et al., Studied the effect of cranioplasty on hemodynamics and cerebral metabolism, found improvement in blood flow and increased regional and general brain metabolism after cranioplasty. They also found that the increase in glucose metabolism after cranioplasty is a sign of good prognosis for patients operated on by decompressive craniectomy [17]. In one study, out of 23 patients with early cranioplasty, 8 weeks after the craniectomy, Liang et al, reported recovery of neurological signs in the majority of patients after early cranioplasty [18]. Other complications are not

\section{Conclusion}

negligible, Yoo et al. [19]. reported an incidence of $13 \% \mathrm{~d}$ subdural hygroma and a $13 \%$ incidence of cranioplasty infection. To analyze infectious complications after craniectomy, a Moroccan study of a series of 170 patients operated by craniectomy, found infectious complications in 30 patients (17.60\%) including 9 patients: scalp infection, 13 meningitis, 3 empyema, 3 abscesses and 2 osteitis. The risk factors identified were the urgency of the surgery, the duration of the surgery $\geq 200$ minutes and the length of stay in the intensive care unit $\geq 72$ hours [20-30]. Guerra et al, found infectious complications in $2 \%$ of the patients. patients included in this study, sub-dural hygroma in $26 \%$ and hydrocephalus in $14 \%$ [21, 31-45].

In a recent study by Rodrigo et al, among 89 patients treated with decompressive craniectomy for severe head trauma, the authors found $34.8 \%$ of patients who developed complications, with hydrocephalus in 7 patients (7.9\%), subdural hydrome in 10 patients $(11.3 \%)$ and infectious complications in 14 patients (15.9\%). Aarabi et al, found in a series of 50 patients treated with decompressive craniectomy, hydrocephalus in 5 patients, hemorrhagic complications in 8 patients and subdural hydrome in 25 patients [9]. Polin et al, reported $28,5 \%$ hydrocephalus after craniectomy [22,46-55]. Su, Ho and Wangont reported a case of subdural hydrome after decompressive craniectomy in a 63-yearold man who suffered a serious head injury resulting in a fronto subdural hematoma. -temporo-parietal with a mass effect. The condition of the patient improved after drainage of the hydromel [23, 56-59]. Kombogiorgas et al, made a retrospective study of 107 children treated with supra-tentorial decompressive craniectomy for several diagnoses, children who were presented with epilepsy are excluded, and the prophylactic anticonvulsant was given to $52 \%$ of children. 12\% (13 children) developed epilepsy (predominantly female), $1.8 \%$ (2 patients) developed postoperative infection.
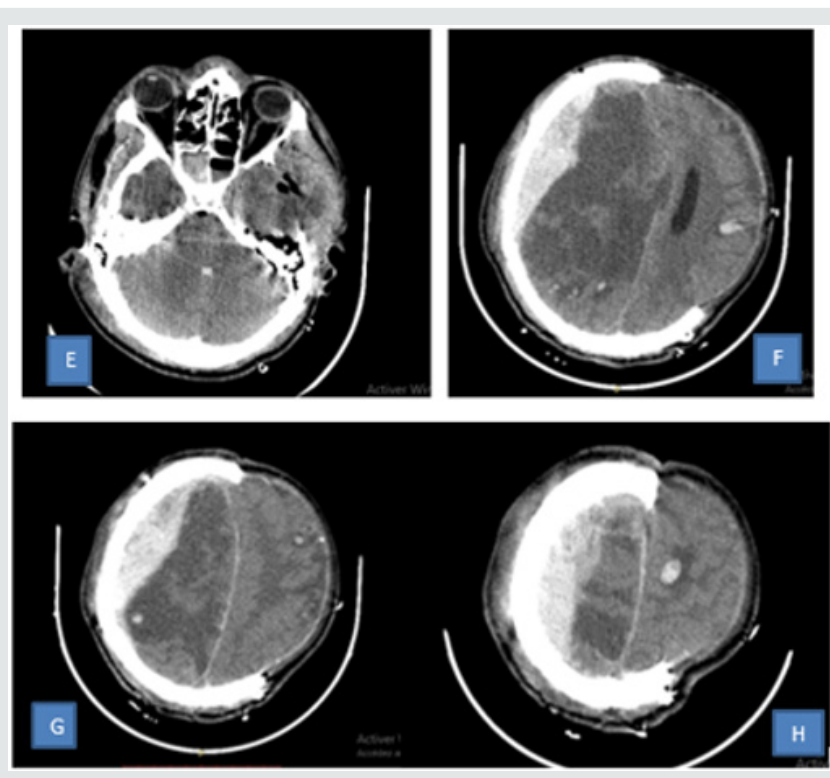

Figure 2: The CT scan done on J1 postoperative $(\mathrm{E}, \mathrm{F}, \mathrm{G}, \mathrm{H})$ shows a herniation of the cerebral parenchyma in a narrower opening of craniectomy with aggravation of foci of hemorrhagic contusion and diffuse edema erasing the cisterns of the base, an extra dural hematoma fronto-temporo-parietal right with quasi-hemispheric ischemia leading to a deviation of the median line and meningeal hemorrhage. 
In relation to the literature, there are more cases of sub-dural hygroma, infection, post-craniectomy epilepsy and extradural hematoma [29]. This leads us to conclude that the controlateral extra-dural hematoma complicating the decompressive component is a real but rare entity whose pathophysiology can be explained by the existence of a post-traumatic contralateral bone lesion clogged by the hard-faced mother. reinforced by the cerebral parenchyma before the craniectomy, the existence of a small vascular lesion in this case the average meningeal artery or one of its branches compressed and pressed against the internal table of the bone by the cerebral parenchyma oedematous via the hard mother before the decompressive craniectomy. In this case the extra dural hematoma is developed after the lifting of the compression via the decompressive craniectomy with herniation of the cerebral parenchyma (Figure 2).

\section{References}

1. Ausman JI, Rogers C, Sharp HL (1976) Decompressive craniectomy for the encephalopathy of Reye's syndrome. Surg Neurol 6(2): 97-99.

2. Masson F, Vecsey J, Salmi LR, Dartigues JF, Erny P, et al. (1997) Disability and handicap five years after a head injury: A population based study. J Clin Epidemiol 50(5): 595-601.

3. Munch E, Horn P, Schurer L, Piepgras A, Paul T, et al. (2000) Management of severe traumatic brain injury bydecompressive craniectomy. Neurosurgery 47(2): 322-323.

4. O Fourcade, Regis Fuzier, A Daboussi, M Gigaud, M Trémoulet, et al. (2006) Decompressive craniectomy and intracranial hypertension. Annales Françaises d Anesthésie et de Réanimation 25(8): 858-862.

5. G. Bouhours, A Ter Minassian, L Beydon (2006) Traumatismes crâniens graves: Prise en charge à la phase initiale Severe head injury: Initial management. Réanimation 15(7-8): 552-560

6. LI Gu, Wen Liang, Yang XF, Zheng XJ, Zhan RY. et al. (2008) Efficacy of large decompressive craniectomy in severe traumatic brain injury. Chinese Journal of Traumatology 2008 11(4): 253-256.

7. Vahedi K (2005) Place of neurosurgery in the treatment of cerebral ischemic attacks. In: Medical Encyclopedia. Elsevier. Neurology, Paris.

8. Bizhan Aarabi, Dale C Hesdorffer, Edward S Ahn, Carla Aresco, Thomas M Scalea, et al. (2006) Outcome following decompressive craniectomy for malignant swelling due to severe head injury. J Neurosurg Volume 10(4): 469-479.

9. Stefini R, Latronico N, Cornali C, Rasulo F, Bollati A (1999) Emergent decompressive craniectomy in patients with fixed dilated pupils due to cerebral venous and dural sinus thrombosis: Report of three cases. Neurosurgery 45(3): 626-629.

10. Dierssen G, Carda R, Coca JM (1983) The influence of large decompressive craniectomy on the outcome of surgical treatment in spontaneous intracerebral haematomas. Acta Neurochir (Wien) 69(1-2): 53-60.

11. Venes JL, Collins WF (1975) Bifrontal decompressive craniectomy in the management of head trauma. J Neurosurg 42(4): 429-433.

12. Ucar T, Akyuz M, Kazan S, Tuncer R (2005) Role of decompressive surgery in the management of severe head injuries: prognostic factors and patient selection. J Neurotrauma 22(11): 1311-1318.

13. Schiffer J, Gur R, Nisim U, Pollak L (1997) Symptomatic patients after craniectomy. Surg Neurol 47(3): 231-237.

14. Uhl E, Kreth FW, Elias B, Goldammer A, Hempelmann RG, et al. (2004) Outcome and prognostic factorsof hemicraniectomy for space occupying cerebral infarction. J Neurol Neurosurg Psychiatry 75 (2): 179-180.
15. Fodstad H, Love JA, Ekstedt J, Fridén H, Liliequist B (1984) Effect of cranioplastyon cerebrospinal fluid hydrodynamics in patients with the syndrome of the trephined. Acta Neurochir (Wien) 70(1-2): 21-30.

16. Timofeev I, Czosnyka M, Nortje J, Smielewski P, Kirkpatrick P, et al. (2008) Effect of decompressive craniectomy on intracranial pressure and cerebrospinal compensation following traumatic brain injury. J Neurosurg 108(1): 66-73.

17. Liang W, Xiaofeng Y, Weiguo L, Gang S, Xuesheng Z, et al. (2007) Cranioplastyof large cranial defect at an early stage after décompressive craniectomy performed for severe head trauma. Journal of craniofacial surgery 18(3): 526-32.

18. Venne D, Salloum A (2004) Decompressive craniectomy: unilateral or bilateral procedure? Masson Paris. 50(5): 91-91.

19. B Idali, B Lahyat, K Khaleq, K Ibahioin, A El Azhari et al. (2004) Postoperative infection after craniotomy in adult Postoperative infection following craniotomy in adults. Medicine and Infectious Diseases 34(5): 221-24.

20. Guerra WKW, Gaab MR, Dietz H, Mueller JU, Piek J, et al. (1999) Surgical decompression for traumatic brain sweelling: indications and results. Neurosurg 90(2): 187-196.

21. Polin RS, Shaffrey ME, Bogaev CA, Tisdale N, Germanson T, et al. (1997) Decompressive bifrontal craniectomyin the treatment of severe refractory posttraumatic cerebral edema. Neurosurgery 41(1): 84-94.

22. Su FW, Ho JT, Wang HC (2008) Acute contralateral subdural hygroma following craniectomy. J Clin Neurosci 15(3): 305-307.

23. Kombogiorgas Dimitris, Jatavallabhula N, Sgouros Spyros, Josan Vivek, Walsh A et al. (2006) Risk factors for developing epilepsy after craniotomy in children. Child's Nervous System 22(11): 1441-1445.

24. Arjona A, Serrano-Castro PJ, Guardado-Santervás P, Maestre-Moreno JF, Olivares J, et al. (2004) Malignant middle cerebral artery infarction: Medical or surgical treatment? Rev Neurol 38(2):145-150.

25. Albanèse J, Leone M, Alliez JR, Kaya JM, Antonini F, et al. (2003) Decompressive craniectomy for severe traumatic brain injury: Evaluation of the effects at one year. Crit Care Med 31(10): 2535-2538.

26. Açikgöz B, Ozcan OE, Erbengi A, Bertan V, Ruacan S, et al. (1986) Histopathological and microdensitometric analysis of craniotomy bone flaps preserved between abdominal fat and muscle. Surg Neurol 26(6): 557-561

27. A El Ouahabi, D Mudjir, Mouden A El Khamlichi (2006) Decompetitive duvolet place in intracranial Hematoma post traumatic. Department of Neurosurgery Specialty Hospital of Rabat XV National Congress of the Moroccan Society of Neurosurgery. Skhirat.

28. Bulger EM, Nathens AB, Rivara FP, Moore M, MacKenzie EJ, et al. (2002) Management of severe head injury: Institutional variations in care and effect on outcome. Crit Care Med 30(8):1870-1876.

29. Cushing $H$ (1905) The establishment of cerebral hernia as a decompressive measure of inaccessible brain tumors with the description of intermuscular methods of making the bone defect in temporal and occipital regions. Surg Gynecol Obstet 1: 297-314.

30. Chen CC, Cho DY, Tsai SC (2007) Outcome of and prognostic factors for decompressive hemicraniectomy in malignant middle cerebral artery infarction. J Clin Neurosci 14(4): 317-321.

31. Chibbaro Salvatore, Tacconi Leonello (2007) Role of decompressive craniectomy in the management of severe head injury with refractory cerebral edema and intractable intracranial pressure. Our experience with 48 cases. Surgical neurology 68(6): 632-638.

32. Charles Philip Toussaint, TC Origitano (2008) Decompressive Craniectomy Review of Indication, Outcome, and Implication Neurosurg Q 18(1). 
33. Csokay A, Egyud L, Nagy L, Pataki G (2002) Vascular tunnel creation to improve the efficacy of decompressive craniotomy in post-traumatic cerebral edema a nd ischemic stroke. Surg Neurol 57(2): 126-129.

34. Cooke RS, Mc Nicholl BP, Byrnes BP (1995) Use of the injury severity score in head injury-Injury 26 (6): 399-400.

35. Dandan JB, James S, Vangrasse A, Born JD (2007) Syndrome protéus et hypertension intracranienne. Neurochirurgie 53(5): 339-42.

36. D Agrawal, N Hussain (2005) Decompressive craniectomy in cerebral toxoplasmosis. Eur J Clin Microbiol Infect Dis 24(11): 772-773.

37. Dabadie P, Bendriss-Vidal P (1992) Traitementde l'hypertension intracrânienne, in MAPAR: Mises au point en Anesthésie Réanimation Paris: MAPAR 569-85.

38. Place Du Volet Decompressif Dans Les Traumatismes Craniens Graves 68

39. Doerfler A, Forsting M, ReithW, et al. (1996) Decompressive craniectomy in a rat model of malignant cerebral hemispheric stroke: experimental support for an agressive therapeutic approach. J Neurosurg 85(5): 853859.

40. Erny P, Cochard JF (1990) Serious Cranial Trauma, in Samii K (ed): Anesthesia Surgical Resuscitation. Paris: Flammarion 1038-49.

41. Flannery T, McConnell RS (2001) Cranioplasty: Why throw the bone flap out? British journal of Neurosurgery 15(6): 518-520.

42. Fisher CM, Ojemann RG (1994) Bilateral decompressive craniectomy for worsening coma in acute subarachnoid hemorrhage. Observations in support of the procedure. Surg Neurol 4(1): 65-74.

43. Frank H. Netter. Atlas of Human Anatomy (4th edn.); Translation of Pierre Kamina MASSON.

44. Orliaguet GA, Meyer PG, Baugnon T (2008) Management of critically il children with traumatic brain injury. Paediatr Anesth 18(6): 455-461.

45. Pierrot M, François V, Minassian AT, Clavier N, Boulard G, et al. (2003) The impact of a French guideline on the clinical management of severe head injury 22(1): 12-17.

46. (1999) Management of severe head trauma in the early phase. Recommendation for clinical practice. How to describe and evaluate the clinical severity of head trauma in order to define the therapeutic strategy at a given time? In Rean Urg 7: 707-715.

47. (1999) Management of severe traumatic brain injury in the early phase. Recommendations for clinical practice. Ann Fr Anesth Reanim 18: 15-22.
48. Partin JC, Partin JS, Schubert WK, McLaurin RL (1975) Brain ultrastructure in Reye's syndrome. J Neuropathol Exp Neurol 34(5): 425-444.

49. Ong YK, Goh KY, Chan C (2002) Bifrontal décompressive craniectomy for acute subdural empyema. Childs Nerv Syst 18(6-7): 340-343.

50. O Coulibaly, K Quenum, Y Sogoba, B Mudjir, I Rifi, et al. (2007) Place of the decompressive component in the management of moderate and severe cranial traumatises. Department of neurosurgery O.N.O specialties hospital, Morocco.

51. Orliaguet GA, Meyer PG, Baugnon T (2008) Management of critically ill children with traumatic brain injury. Paediatr Anesth 18(6): 455-461.

52. Pierrot M, François V, Minassian AT, Clavier N, Boulard G, et al. (2003) The impact of a French guideline on the clinical management of severe head injury (SHI) published in 1999. Ann Fr Anesth Reanim 22(1): 1217.

53. Salvatore C, Marco M, Antonio R, Salvatore I, Eugenio B (2008) Combined internal uncusectomy and decompressive craniectomy for the treatment of severe closed head injury: Experience with 80 cases. J Neurosurg 108(1): 74-79.

54.Skoglund Thomas S, Eriksson-Ritzen Catherine, Jensen Christer, Rydenhag Bertil (2006) Aspects on decompressive craniectomy in patients with traumatic head injuries. Journal of neurotrauma 23(10): 1502-1509.

55. Schneider GH, Bardt T, Lanksch WR, Unterberg A (2002) Decompressive craniectomy following traumatic brain injury: ICP, CPP and neurological outcome. Acta Neurochir 81: 77-79.

56. Smith E, Carter B, Ogilvy C (2002) Proposed use of prophylactic decompressive craniectomy in poor-grade aneurysmal subarachnoid hemorrhage patients presenting with associated large sylvian hematomas. Neurosurgery 51(1): 117-124.

57. Schaller B, Graf R, Sanada Y, Rosner G, Wienhard K,Heiss WD (2003) Hemodynamic andmetabolic effects of decompressive hemicraniectomy in normal brain.An experimental PET-study in cats. Brain Res 982(1): 31-37.

58. Ter Minassian A (2003) Multimodal monitoring in neuro-resuscitation. Elsevier, Update Conference. 755-772.

59. Winter CD, Adamides A, Rosenfeld JV (2005) The role of decompressive craniectomy in the management of traumatic brain injury: A critical review. J Clin Neurosci 12(6): 619-623.

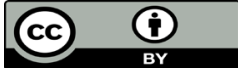

This work is licensed under Creative Commons Attribution 4.0 License

To Submit Your Article Click Here:

Submit Article

DOI: $10.32474 / 0 J N B D .2019 .03 .000160$

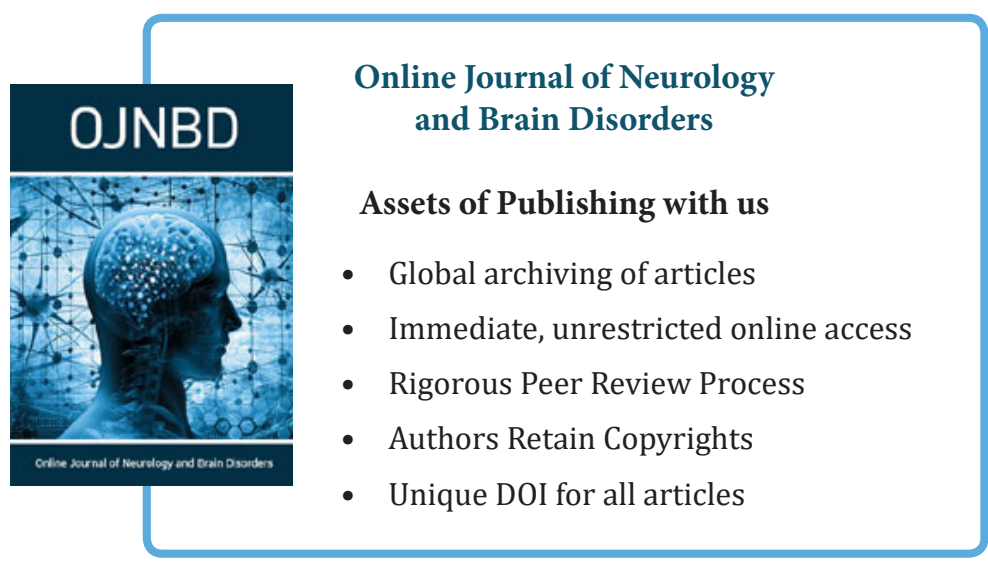

